\title{
Author's index
}

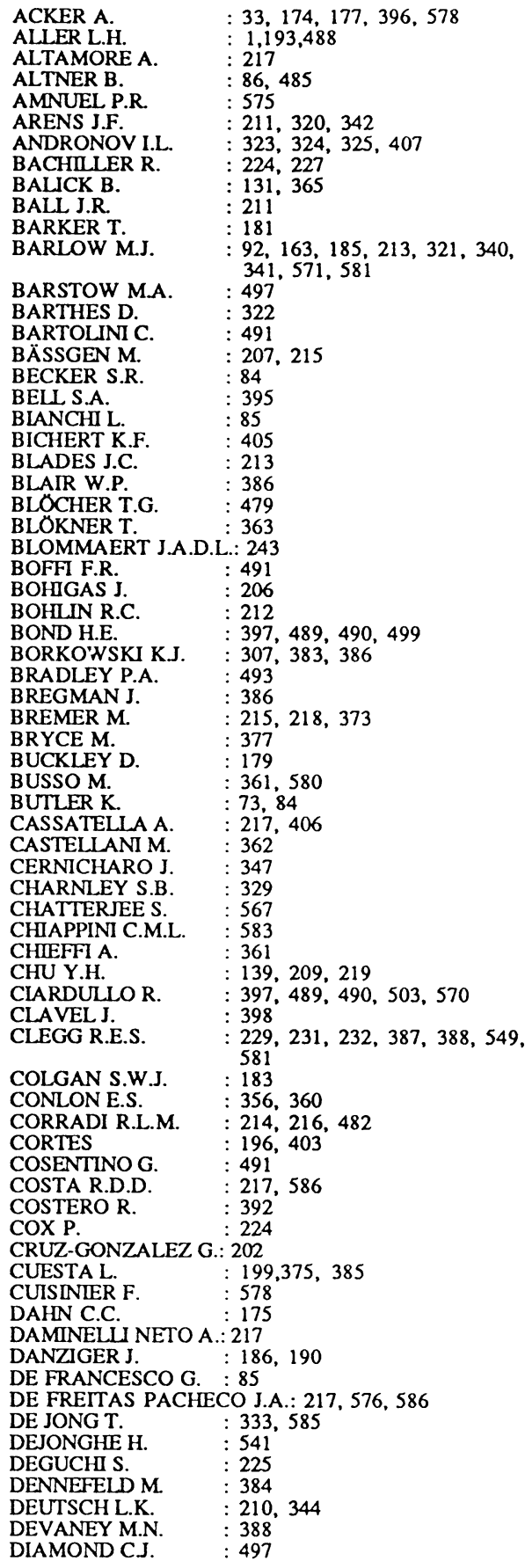

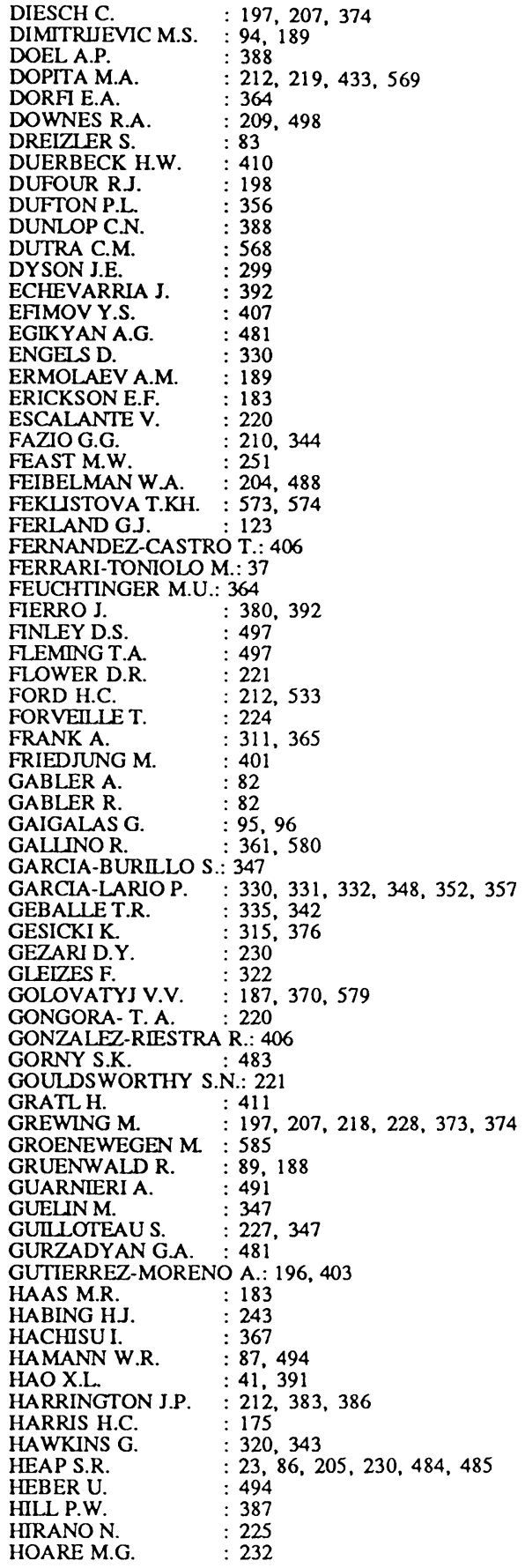




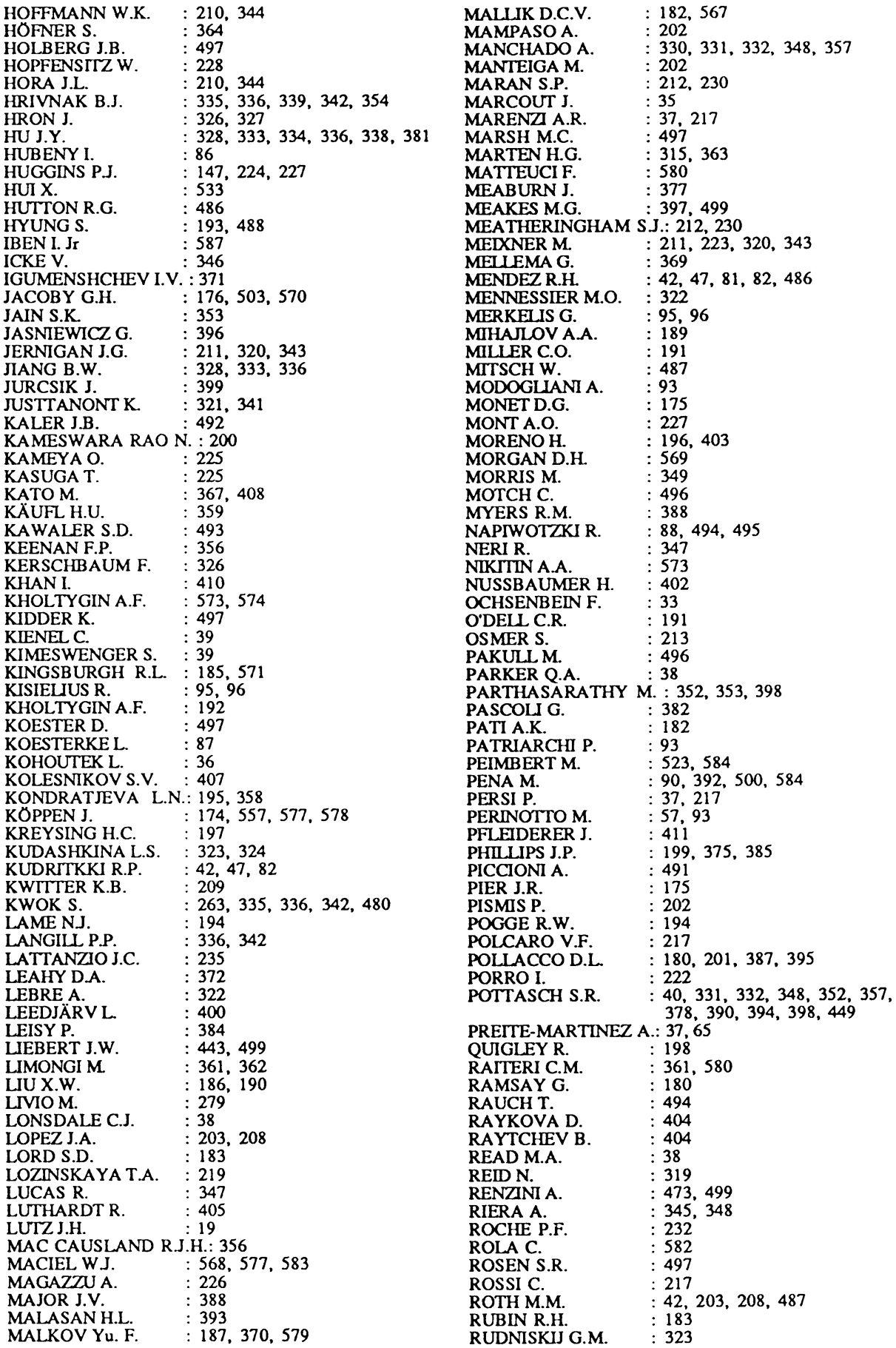




$\begin{array}{ll}\text { RUDZKAS Z. } & : 96 \\ \text { RUIZ M.T. } & : 91,500,584 \\ \text { SAGER R. } & : 182 \\ \text { SAHAI R. } & : 229 \\ \text { SAHAL-BRECHOT S. }: 94 \\ \text { SAHU K.C. } & : 271,357,378 \\ \text { SAMIAD M. } & : 174 \\ \text { SANSOM A.E. } & : 497 \\ \text { SAPAR A.A. } & : 573 \\ \text { SASSELOV D.D. } & : 259 \\ \text { SAURER W. } & : 43,178 \\ \text { SEAQUIST E.R. } & : 406 \\ \text { SCARROTT S.M. } & : 3 \\ \text { SCHMID H.M. } & : 402 \\ \text { SCHNEIDER S.E. } & : 179 \\ \text { SCHONBERNER D. } & : 415,479,495 \\ \text { SCHUSTER W.J. } & : 392 \\ \text { SCHWARZ H.E. } & : 214,216,482 \\ \text { SHAKHOVSKOY N.M.: } 407 \\ \text { SHARPLES R.M. } & : 388 \\ \text { SHAW R.A. } & : 492 \\ \text { SHIBATA K.M. } & : 225 \\ \text { SHIVANANDAN K. } & : 210,344 \\ \text { SHORE S.N. } & : 230 \\ \text { SILVESTRO G. } & : 222 \\ \text { SILVOTTI R. } & : 491 \\ \text { SIMPSON J.P. } & : 183 \\ \text { SIONE.M. } & : 498 \\ \text { SKINNER C.J. } & : 211,320,321,341,343 \\ \text { SLIJKHUIS S. } & : 333,337 \\ \text { SMTH R.G. } & : 329 \\ \text { SOFFNER T. } & : 487 \\ \text { STANGHELLINI L } & : 184,214,359,473,482,491, \\ & : 179,461,582 \\ \text { STASINSKA G.F. } & : 197 \\ \text { STAUBERT R. } & : 197 \\ \text { STECHER T.P. } & : 212 \\ \text { STENCEL R.E. } & : 405 \\ \text { STENHOLM B. } & : 11,174,177 \\ \text { STOREY PJ. } & : 92 \\ \text { STRANIERO O. } & : 361 \\ \text { STRAZZULLA G. } & : 226 \\ \text { SURENDIRANATH R.: } 200 \\ \text { SYLVESTER R.J. } & : 321 \\ \text { SZCZERBA R. } & : 315,350,363,376 \\ \text { TAKANO R. } & : 366 \\ & \end{array}$

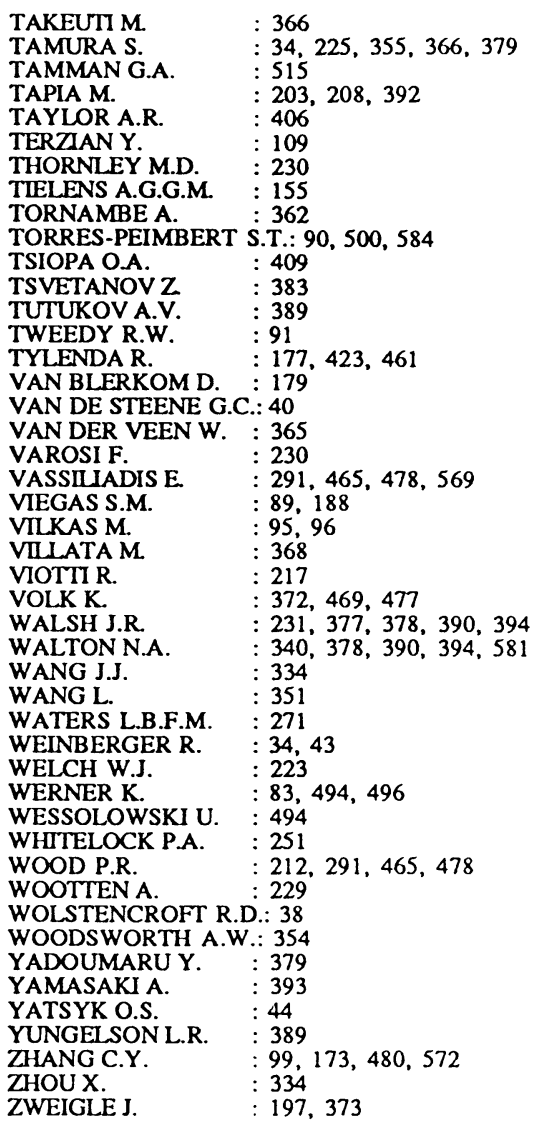

